\title{
Introduction to special section on the Phoenix Mission: Landing Site Characterization Experiments, Mission Overviews, and Expected Science
}

P. H. Smith, ${ }^{1}$ L. Tamppari, ${ }^{2}$ R. E. Arvidson, ${ }^{3}$ D. Bass, ${ }^{2}$ D. Blaney, ${ }^{2}$ W. Boynton, ${ }^{1}$

A. Carswell, ${ }^{4}$ D. Catling, ${ }^{5}$ B. Clark, ${ }^{6}$ T. Duck, ${ }^{7}$ E. DeJong, ${ }^{2}$ D. Fisher, ${ }^{8,9}$ W. Goetz, ${ }^{10}$

P. Gunnlaugsson, ${ }^{11}$ M. Hecht,${ }^{2}$ V. Hipkin, ${ }^{12}$ J. Hoffman, ${ }^{13}$ S. Hviid, ${ }^{10}$ H. Keller, ${ }^{10}$

S. Kounaves, ${ }^{14}$ C. F. Lange, ${ }^{15}$ M. Lemmon, ${ }^{16}$ M. Madsen,,${ }^{17}$ M. Malin, ${ }^{18}$ W. Markiewicz,${ }^{10}$

J. Marshall, ${ }^{19}$ C. McKay, ${ }^{20}$ M. Mellon, ${ }^{21}$ D. Michelangeli, ${ }^{22,23}$ D. Ming, ${ }^{24}$ R. Morris, ${ }^{24}$

N. Renno, ${ }^{25}$ W. T. Pike, ${ }^{26}$ U. Staufer, ${ }^{27}$ C. Stoker, ${ }^{20}$ P. Taylor, ${ }^{22}$ J. Whiteway, ${ }^{22}$

S. Young, ${ }^{14}$ and A. Zent ${ }^{20}$

Received 21 January 2008; accepted 26 June 2008; published 15 October 2008.

[1] Phoenix, the first Mars Scout mission, capitalizes on the large NASA investments in the Mars Polar Lander and the Mars Surveyor 2001 missions. On 4 August 2007, Phoenix was launched to Mars from Cape Canaveral, Florida, on a Delta 2 launch vehicle. The heritage derived from the canceled 2001 lander with a science payload inherited from MPL and 2001 instruments gives significant advantages. To manage, build, and test the spacecraft and its instruments, a partnership has been forged between the Jet Propulsion Laboratory, the University of Arizona (home institution of principal investigator P. H. Smith), and Lockheed Martin in Denver; instrument and scientific contributions from Canada and Europe have augmented the mission. The science mission focuses on providing the ground truth for the 2002 Odyssey discovery of massive ice deposits hidden under surface soils in the circumpolar regions. The science objectives, the instrument suite, and the measurements needed to meet the objectives are briefly described here with reference made to more complete instrument papers included in this special section. The choice of a landing site in the vicinity of $68^{\circ} \mathrm{N}$ and $233^{\circ} \mathrm{E}$ balances scientific value and landing safety. Phoenix will land on 25 May 2008 during a complex entry, descent, and landing sequence using pulsed thrusters as the final braking strategy. After a safe landing, twin fan-like solar panels are unfurled and provide the energy needed for the mission. Throughout the 90 -sol primary mission, activities are planned on a tactical basis

\footnotetext{
${ }^{1}$ Department of Planetary Sciences, University of Arizona, Tucson, Arizona, USA

${ }^{2}$ Jet Propulsion Laboratory, California Institute of Technology, Pasadena, California, USA.

${ }^{3}$ Department of Earth and Planetary Sciences, Washington University, St. Louis, Missouri, USA.

${ }^{4}$ Optech Inc., Vaughan, Ontario, Canada.

${ }^{5}$ Department of Earth Sciences, University of Bristol, Bristol, UK.

${ }^{6}$ Lockheed Martin, Littleton, Colorado, USA.

${ }^{7}$ Department of Physics and Atmospheric Science, Dalhousie University, Halifax, Nova Scotia, Canada.

${ }^{8}$ Geological Survey of Canada, Ottawa, Ontario, Canada.

${ }^{9}$ Also at Department of Earth Sciences, University of Ottawa, Ottawa, Ontario, Canada.

${ }^{10}$ Max Planck Institute for Solar System Research, Katlenburg-Lindau, Germany.

${ }^{11}$ Department of Physics and Astronomy, University of Aarhus, Aarhus, Denmark.

${ }^{12}$ Canadian Space Agency, Saint-Hubert, Quebec, Canada.

${ }^{13}$ Physics Department, University of Texas, Dallas, Texas, USA.

${ }^{14}$ Department of Chemistry, Tufts University, Medford, Massachusetts, USA.

Copyright 2008 by the American Geophysical Union. 0148-0227/08/2008JE003083
}

\footnotetext{
${ }^{15}$ Department of Mechanical Engineering, University of Alberta, Edmonton, Alberta, Canada.

${ }^{16}$ Department of Atmospheric Sciences, Texas A\&M University, College Station, Texas, USA.

${ }^{17}$ Earth and Planetary Physics, Niels Bohr Institute, University of Copenhagen, Copenhagen, Denmark.

${ }^{18}$ Malin Space Science Systems, San Diego, California, USA.

${ }^{19}$ SETI Institute, Mountain View, California, USA.

${ }^{20}$ Space Science Division, NASA Ames Research Center, Moffett Field, California, USA.

${ }^{21}$ Laboratory for Atmospheric and Space Physics, University of Colorado, Boulder, Colorado, USA.

${ }^{22}$ Department of Earth and Space Science and Engineering, York University, Toronto, Ontario, Canada.

${ }^{23}$ Deceased 30 August 2007.

${ }^{24}$ Johnson Space Center, Houston, Texas, USA.

${ }^{25}$ Department of Atmospheric, Oceanic and Space Sciences, University of Michigan, Ann Arbor, Michigan, USA.

${ }^{26}$ Department of Electrical and Electronic Engineering, Imperial College London, London, UK.

${ }^{27}$ Institute of Microtechnology, University of Neuchâtel, Neuchâtel, Switzerland.
} 
by the science team; their requests are passed to an uplink team of sequencing engineers for translation to spacecraft commands. Commands are transmitted each Martian morning through the Deep Space Network by way of a Mars orbiter to the spacecraft. Data are returned at the end of the Martian day by the same path. Satisfying the mission's goals requires digging and providing samples of interesting layers to three on-deck instruments. By verifying that massive water ice is found near the surface and determining the history of the icy soil by studying the mineralogical, chemical, and microscopic properties of the soil grains, Phoenix will address questions concerning the effects of climate change in the northern plains. A conclusion that unfrozen water has modified the soil naturally leads to speculation as to the biological potential of the soil, another scientific objective of the mission.

Citation: Smith, P. H., et al. (2008), Introduction to special section on the Phoenix Mission: Landing Site Characterization Experiments, Mission Overviews, and Expected Science, J. Geophys. Res., 113, E00A18, doi:10.1029/2008JE003083.

\section{Introduction: Scout Selection Process}

[2] Phoenix is the first Mars Scout mission: a Principal Investigator (PI) led mission selected through a two-stage proposal process. Scouts are similar to Discovery-class missions except that the target object must be Mars. About two dozen proposals were developed and submitted for evaluation during the step 1 portion of the Scout selection process. Scientific merit was the primary consideration used for grading the proposed missions along with reasonable expectance of low-to-medium risk during implementation. In December 2002 four mission concepts were selected for step 2 of the proposal evaluation process, also called phase A or formulation. The Scouts had an unusually short and underfunded phase A period compared to other Mars missions, but the competitive nature of the enterprise pushed the four proposal teams to excellent mission concepts. Proposals were submitted in May 2003 and reviewed by the TMCO (Technical, Management, Cost, and Other) board for mission worthiness: no attempt was made to reevaluate the scientific merit that was accepted during step 1. In July 2003 each team conducted a site visit for the TMCO reviewers to further elucidate the mission concepts and answer questions that the reviewers had submitted. Finally, in early August 2003, the Phoenix mission was selected to proceed with phase B, preliminary design, and in June 2005 was confirmed to proceed to completion.

[3] This paper provides an overview of the mission and its goals and serves as an introduction to a series of papers that provide in-depth descriptions of each science instrument including the design concepts, the requirements levied, the operational modes, the calibration parameters, and the expected performance. In addition, there are also papers on the landing site selection process, atmospheric models of the region, and the operational plans for the surface mission. The intention is that this series of papers will inform interested scientists about the Phoenix mission and serve as a guide during and after the mission.

\section{Phoenix Mission}

\subsection{Vision}

\subsubsection{Explore the Near-Surface Ice in the Martian} Arctic

[4] The inspiration for the Phoenix mission evolved from a series of discussions between Chris McKay and Carol
Stoker from the Ames Research Center, John Marshall of the SETI Institute, Mike Hecht from JPL, and Peter Smith at the University of Arizona. The original concept was to keep costs low using the existing 2001 lander, whose mission had been canceled in 2000, along with its instrument suite augmented by rebuilds of key instruments from the Mars Polar Lander. Smith, who had been a participant on both these missions, was chosen as PI and tasked with finding a worthy science goal for the mission.

[5] The first major discovery of the Odyssey mission was just being announced in February 2002 by the Gamma Ray Spectroscopy (GRS) team [Boynton et al., 2002; Mitrofanov et al., 2002; Feldman et al., 2002]. Significant deposits of ice were discovered surrounding the southern polar cap as far north as $60^{\circ}$; there was also a hint of similar hidden water reservoirs in the northern polar region which, at the time, was covered by a winter blanket of carbon dioxide ice. Clearly a mission without mobility, yet having the capability to dig beneath the surface, would allow for in situ verification of this discovery. The Phoenix mission was developed around the goal of understanding the implications of the buried ice reservoir in relation to the larger Martian exploration goals set forth by the Mars Exploration Program Advisory Group (MEPAG).

\subsubsection{Relevant MEPAG and NASA Goals}

[6] The MEPAG has organized their recommendations into four major goals; these have been endorsed by NASA and serve as guideposts in evaluating the science merit of Mars missions. Many of these goals and their investigations are addressed by the Phoenix mission. The complete MEPAG document is available at $\mathrm{http}: / /$ mepag.jpl.nasa.gov; the following discussion is taken from the February 2006 version of the scientific goals.

[7] MEPAG goal 1 is to "determine if life ever arose on Mars." Clearly, proving the negative is not possible, so the strategy is to characterize environment by environment for habitability as a stepping stone on the path that leads eventually to understanding the biology of potential Martian life forms.

[8] The key word is habitability. MEPAG sets the following minimum criteria: (1) the presence of liquid water, (2) the presence of key elements that provide the raw material to build cells, and (3) a source of energy to support life.

[9] The primary focus at this beginning stage in the search for Martian life is finding near surface sources of 
liquid water. None are known in the current era, but largescale angular changes in obliquity and variations in the orbital dynamics offer possibilities for climate change over the last few million years that create conditions favorable for melting ice or snow. The gullies found by Malin and Edgett [2000] may have been caused by snowmelt [Christensen, 2003] and may well be an indication of recent climate change. The northern plains are specifically identified because of the colocation of massive ground ice and air pressure above the triple point of water. It is still an open question whether the temperature ever reaches the melting point where these conditions prevail.

[10] A second investigation is to model the processes that cause water to move from one reservoir to another. Vapor diffusion models have been investigated that predict the transport and accumulation of water vapor into the subsurface ice in the polar regions. These models agree well with Odyssey measurements. However, the amount of ice in the polar regions exceeds that diffused into pore spaces and another source is implied.

[11] A third investigation here is to identify and characterize phases containing $\mathrm{C}, \mathrm{H}, \mathrm{O}, \mathrm{N}, \mathrm{P}$ and $\mathrm{S}$ including minerals, ices, and gases, and the fluxes of these elements between phases. Carbon in the form of complex organics is the best indication of a habitable zone and a strong biosignature. The isotopic fractionation of the carbon is another important biosignature. Nitrogen, phosphorus and sulfur are critical elements for life on Earth and the likely abundances are difficult to detect from orbit. Sulfates have been identified by the Opportunity rover [Squyres et al., 2004] as a major component of the ancient sedimentary rocks, but nitrates and Phosphates are more difficult to detect. Phoenix can only detect them in large concentrations.

[12] The final investigation is to determine the array of potential energy sources available to sustain biological processes. Sources of energy that should be measured include chemical redox pairs, $\mathrm{pH}$ gradients, geothermal heat, radioactivity, insolation, and atmospheric processes. In polar permafrost environments on the Earth, regions of oxidation and salt-rich layers created through the action of unfrozen water are common.

[13] MEPAG goal 2 is to "understand the processes and history of climate on Mars." Of relevance here is the ability of landed missions to provide direct in situ measurements of conditions that control the exchange of volatiles and dust between the surface and atmosphere. In addition, the history of the atmosphere can be studied by determining the stable isotopic, noble gas, and trace gas compositions of the present-day atmosphere.

[14] Another objective that applies to surface missions is to understand the thermal and dynamical behavior of the planetary boundary layer. Turbulence from convective cells and winds over a rough surface can disturb the lower atmosphere to about $5 \mathrm{~km}$ altitude. This layer is particularly difficult to study from orbit and models are poorly constrained. Tracking the boundary layer characteristics through diurnal and seasonal time scales is also considered important.

[15] The third MEPAG goal is to "determine the evolution of the surface and interior of Mars." A polar lander can contribute to this goal by characterizing the surface- atmosphere interactions and the morphology, chemistry and mineralogy of surface rocks and alteration products.

[16] The fourth MEPAG goal is preparation for human missions. Surface missions help by identifying resources and hazards as well as understanding the properties of the atmosphere with respect to aerobraking and entry, descent, and landing factors. Identification of hazardous dust properties is included here.

\subsubsection{Orbital Variations and Obliquity Changes}

[17] Because of the focus of the MEPAG document on liquid water, discussion of the climate variations in recent Mars history is worth recount. Part and parcel to the question of whether the arctic ice has reached the melting temperature [Haberle et al., 2001] are the forcing factors of the orbital dynamics and associated obliquity variations. Laskar et al. [2004] have calculated these factors and the associated changes in polar insolation back $10 \mathrm{Ma}$. The characteristic time scale is $51 \mathrm{Ka}$ between peaks that corresponds to the precession of the spin axis. A longer scale is calculated where a large shift occurs about $1 \mathrm{Ma}$ tilting the rotation axis toward the orbital plane and increasing the solar heating of the polar regions.

[18] Using the Laskar model, Forget et al. [2006a] have calculated the effects that these induced insolation variations have on the polar ices. The extreme tilts will force the ice to sublimate away from the polar regions to the equatorial highlands forming glaciers. Evidence of these periodic glaciers has been reported by Head et al. [2005] near Arsia Mons. Drop moraines, sublimation till, and lobate deposits indicate the active cycle of a glacier that appears to have vanished.

[19] As the obliquity veers away from the highest values above $45^{\circ}$ to a more perpendicular position, the ice returns to the polar region [Forget et al., 2006b]. This is not accomplished in a single step; ice that has accumulated in the equatorial regions becomes unstable and is transported slowly through the thin atmosphere toward the poles. The models require the deposition of large amounts of water ice at latitudes near $60^{\circ}$ across all longitudes: perhaps the source of the subsurface ice seen by Odyssey. Eventually, the migration completes and only the polar cap is exposed as we observe it today. This process may have repeated many times throughout Martian history, leading to layered ice deposits and the periglacial features seen on the western sides of the large volcanoes [Levrard et al., 2004].

[20] The Phoenix mission will attempt to find evidence in the surface mineralogy and chemistry to support this theory of migratory ices. The signatures are expected to be strongest if the ice undergoes a melted phase and wets the soil. This is a major goal of the Phoenix mission and is described below.

\subsubsection{Build on Existing Hardware and Experience}

[21] Any proposal responding to Scout requirements must find a method to keep costs low. The Phoenix namesake is the mythological bird that after a 500-year life died in flames and was reborn from the ashes. The Phoenix mission derives its heritage from the 2001 lander that was canceled in 2000 after the failure of the Mars Polar Lander (MPL) to return any signals after entering the Martian atmosphere in December 1999. The instrument suite is chosen from the MPL and 2001 instruments, receiving the advantage of not 
only the existing hardware, but the engineers, scientists, and technicians who retained the knowledge of the engineering design and history.

[22] Lockheed Martin in Denver (LM) has maintained the 2001 lander under contract from NASA since the cancellation and many of the original crew joined the Phoenix project. A large box in their clean room contained the fully assembled spacecraft except for some parts that had been borrowed by the Mars Exploration Rover (MER) and Mars Reconnaissance Orbiter (MRO) projects.

[23] Several instruments on the 2001 lander were maintained in a flight-ready condition. These included the Robotic Arm (RA) with its camera (RAC) and the Microscopy, Electrochemistry, and Conductivity Analyzer (MECA) suite of instruments. Rebuilt from the MPL mission were the Thermal and Evolved Gas Analyzer (TEGA) and Surface Stereo Imager (SSI). To complete the instrument suite, a weather station (MET) including a powerful lidar was contributed by the Canadian Space Agency (CSA).

\subsubsection{Faster-Better-Cheaper Era}

[24] Phoenix relies on the NASA investment in two previous missions, the inheritance of the majority of the flight hardware, and foreign contributions to keep the costs low. The major strength of Phoenix is the existing hardware that allows a start in the test phase of the program. The major weakness is that the inherited hardware was designed during the faster-better-cheaper era when NASA decreased the risk tolerance and mission assurance policies were more freewheeling. Therefore, documentation and reliability engineering were not performed to the standards applied today.

\subsection{First Scout Mission}

\subsubsection{Partners}

[25] Phoenix finds a balance between private industry, universities, and NASA centers. LM provides the spacecraft and is responsible for refurbishing the 2001 Surveyor lander. LM had designed the lander on the basis of its series of Mars craft that started with Mars Global Surveyor (MGS), then MPL and Mars Climate Orbiter (MCO) and finally the 2001 lander and the Odyssey orbiter. In addition, LM applied similar technologies to two Discovery missions: Genesis and Stardust.

[26] To manage the large contract at LM, JPL was chosen for their close relationship with LM on the successful MRO project that was under development as Phoenix started. JPL brings a wealth of experience to the mission including system engineering, mission operations and navigation, mission assurance, and payload management. Their record of successful landings on Mars with Pathfinder and the two MER rovers cannot be equaled.

[27] The science expertise for the mission is found primarily within the University system both in the United States and abroad. Instrument teams at JPL and the University of Arizona (UA) are joined by the Canadian MET team and by groups in Denmark, Germany, and Switzerland to form a multinational team bringing scientists and their instruments together to understand the northern plains from many perspectives.

[28] Since the PI, Peter Smith, is from the UA along with William Boynton who is the science co-I for the TEGA team, Smith proposed to operate the science phase of the
Table 1. Phoenix Timeline

\begin{tabular}{lll}
\hline Phase & \multicolumn{1}{c}{ Date } & \multicolumn{1}{c}{ Activity } \\
\hline A & 1 Jan 2003 & formulation, part of proposal competition \\
& 16 May 2003 & $\begin{array}{l}\text { delivery of concept study report } \\
\text { selection }\end{array}$ \\
4 Aug 2003 & payload development, hot fire testing \\
B & 1 Sep 2003 & project management/systems review \\
& 20 Mar 2004 & flight system heritage reviews \\
& Sep-Nov 2004 & preliminary design review \\
& Feb 2005 & confirmation review passed \\
C/D & Jun 2005 & payload flight builds, flight system restoration \\
& Jun 2005 & critical design review \\
& Nov 2005 2005 & begin payload interoperability testing at UA \\
Mar 2006 & start assembly, test and launch operations \\
& Jun 2006 & deliver flight instruments \\
May 2007 & start Kennedy Space Center operations \\
4 Aug 2007 & launch on Delta II \\
4 Sep 2007 & cruise, EDL, and surface operations \\
25 May 2008 & separation, entry, descent, and landing \\
26 May 2008 & start primary mission \\
24 Aug 2008 & start extended mission \\
16 Nov 2008 & enter solar conjunction, end of mission \\
16 Apr 2009 & all data archived \\
\hline
\end{tabular}

mission from the UA. The UA agreed to supply the project with an operations center and offer full support during the landed mission. Therefore, the mission management will relocate from JPL to the UA as soon as the spacecraft is judged to be safely on the Martian surface.

\subsubsection{Timeline}

[29] Table 1 shows the Phoenix timeline. A long phase B allowed time to review the heritage of the hardware and to conduct the tests that were identified in the return-to-flight review (T. Young et al., Mars Program Independent Assessment Team (MPIAT) summary report, 2000, available at http://spaceflight.nasa.gov/spacenews/releases/2000/mpl/ mpiat_summary.pdf). This review was conducted after the MPL failure and tasked with finding the necessary steps to bring the 2001 lander up to an acceptable risk level. Tom Young, who had been the Viking mission director, was asked to chair this review. Because of the time that was required to prepare and conduct these new tests, the 2001 lander could not meet the schedule for launch and was canceled. The Phoenix project allowed time for these activities and all tests judged feasible were conducted and passed. The lessons learned during these tests were incorporated into the design.

[30] The instruments which had to be rebuilt were in many cases the pacing factor; they were started early and managed by payload manager, M. Gross. As testimony to the exceptional performance of the payload teams, all instruments met their primary delivery goal in June/July 2006. In some cases engineering components were later swapped with flight models in April 2007.

\subsubsection{Science Team}

[31] Phoenix has a large science team garnered from the U.S., Canada, and Europe. Many of our scientists are instrument coinvestigators who assure the science integrity of the instruments by reviewing the requirements, overseeing the validation and verification $(\mathrm{V} \& \mathrm{~V})$ program that proves the requirements are achieved, by participating in the calibration of the instrument, and by characterizing the instrument under operational conditions. The instruments and the scientists who oversee them are listed in Table 2. 
Table 2. Instrument Suite on the Phoenix Mission

\begin{tabular}{|c|c|c|}
\hline Instrument (Lead Institution) & Subinstrument & Lead Scientist \\
\hline Surface Stereo Imager (SSI) (UA) & & M. Lemmon (Texas A\&M) \\
\hline Robotic Arm Camera (RAC) (MPSS, Germany) & & H. U. Keller (MPSS) \\
\hline \multirow[t]{2}{*}{ Thermal and Evolved Gas Analyzer (TEGA) (UA) } & Thermal Analyzer (TA) & W. Boynton (UA) \\
\hline & Evolved Gas Analyzer (EGA) & W. Boynton (UA), J. Hoffman (UTD) \\
\hline $\begin{array}{l}\text { Microscopy, Electrochemistry, and Conductivity } \\
\text { Analyzer (MECA) (JPL) }\end{array}$ & Optical Microscope (OM) & J. Marshall (SETI) \\
\hline \multirow[t]{3}{*}{ M. Hecht, overall lead scientist (JPL) } & Atomic Force Microscope (AFM) & U. Staufer (U. Neuchatel, Switzerland) \\
\hline & Wet Chemistry Lab (WCL) & S. Kounaves (Tufts) \\
\hline & $\begin{array}{l}\text { Thermal and Electrical Conductivity } \\
\text { Probe (TECP) }\end{array}$ & A. Zent (NASA Ames) \\
\hline \multirow[t]{2}{*}{ Robotic Arm (RA) (JPL) } & RA + biobarrier & R. Arvidson (Wash. U.) \\
\hline & scoop + rasp & R. Arvidson (Wash. U.) \\
\hline \multirow{5}{*}{ MET (CSA, MDA) } & lidar & J. Whiteway (York U., Canada) \\
\hline & pressure & P. Taylor (York U., Canada) \\
\hline & temperature & P. Taylor (York U., Canada) \\
\hline & wind sensor & P. Gunnlaugsson (U. Aarhus, Denmark) \\
\hline & temperature mast & \\
\hline Magnetic targets (U. Copenhagen, Denmark) & & M. Madsen (U. Copenhagen, Denmark) \\
\hline Atmospheric Structure Experiment (ASE) (JPL) & & D. Catling (U. Bristol, Great Britain) \\
\hline
\end{tabular}

[32] Other scientists did not participate in the instrument development in an intimate way and are divided into four teams called Science Theme Groups. The divisions are as follows: atmospheres, geology, chemistry and mineralogy, and biological potential. While the disciplines of the first three groups are fairly obvious, the last has the difficult task of incorporating the science output of the other groups and coming to an evaluation of the biological potential of the site. This is often referred to as habitability, as regards microbes not humans.

[33] Finally, scientists on the team can join working groups on various topics. The landing site working group has seen the most activity thus far. Other groups are planetary protection and contamination, surface operations, archiving, and other short-lived working groups as needed.

\subsubsection{Management Structure}

[34] The backbone of the project team is the PI connection to the project manager (PM) at JPL, B. Goldstein, and through him and his flight system manager to the LM manager, E. Sedivy. During the development and cruise phases, everything else branches from this central column.

[35] The PI has full responsibility for guiding the project to meet the science goals that have been formalized in the Phoenix Level 1 Requirements document signed by NASA headquarters. No deviations can be made from this document without notification and agreement from all signatories. A description of these high-level goals is found in section 3. Helping to meet these requirements, the PI works closely with the project scientist, L. Tamppari, and her staff at JPL. She has the responsibility of informing and organizing the science team as well as representing the science perspective during engineering development meetings.

[36] The Phoenix PI is also responsible for building and maintaining the Science Operations Center and managing the Education/Public Outreach program. The UA, as a condition of proposal acceptance, has provided a $50,000 \mathrm{sq}$. $\mathrm{ft}$. building for use as an operations center and offices for project personnel. One section of the building is converted into a Mars simulation environment to test the interoperability of the instrument package under realistic Mars-like conditions. It is not possible to duplicate the atmospheric environment in this facility, but a broad set of soil conditions can be simulated, including supercooled ice, and Mars lighting conditions to prepare the team for likely environments on Mars.

[37] The project office at JPL controls the day-to-day management of the work plan designed to meet project goals within the cost constraints negotiated with the Mars program office. The PM with his support staff directly manages the flight system office, the system engineering team, the mission systems group, and the mission assurance team. JPL is also responsible for the interface between the spacecraft and the Delta II launch vehicle.

[38] LM interacts with JPL and the project office through the flight system manager who holds the contract and negotiates any changes. The LM team is divided into groups according to the subsystems (propulsion, communications, power, thermal, structures, software, and so on) that make up the spacecraft and the phases of the mission: launch, cruise, entry-descent-landing (EDL), and surface operations. They also have a system engineering team and mission assurance group. LM follows the institutional procedures that they have developed through years of building spaceflight hardware and many lessons learned.

\subsubsection{Building Reliability Into Heritage Hardware}

[39] Early reviews of the Phoenix project led to recommendations by a review board of engineering experts that a complete assessment of the inherited hardware needed to be conducted with the goal of meeting mission assurance guidelines and checking that proper reliability engineering was available. The subsystems on Phoenix bring heritage although some subsystems were slightly modified. The new builds and major modifications are the solar arrays, UHF low gain antennas, the parachute and its attachment structure, the landing radar, and the MET instrument from Canada.

[40] A year after selection, 12 reviews were conducted, one for each subsystem. Much of the documentation associated with the original design and building of the spacecraft was not available and needed to be regenerated in some cases. Proof that reliability engineering practices had been implemented was lacking. This led to a period of revalidating the 


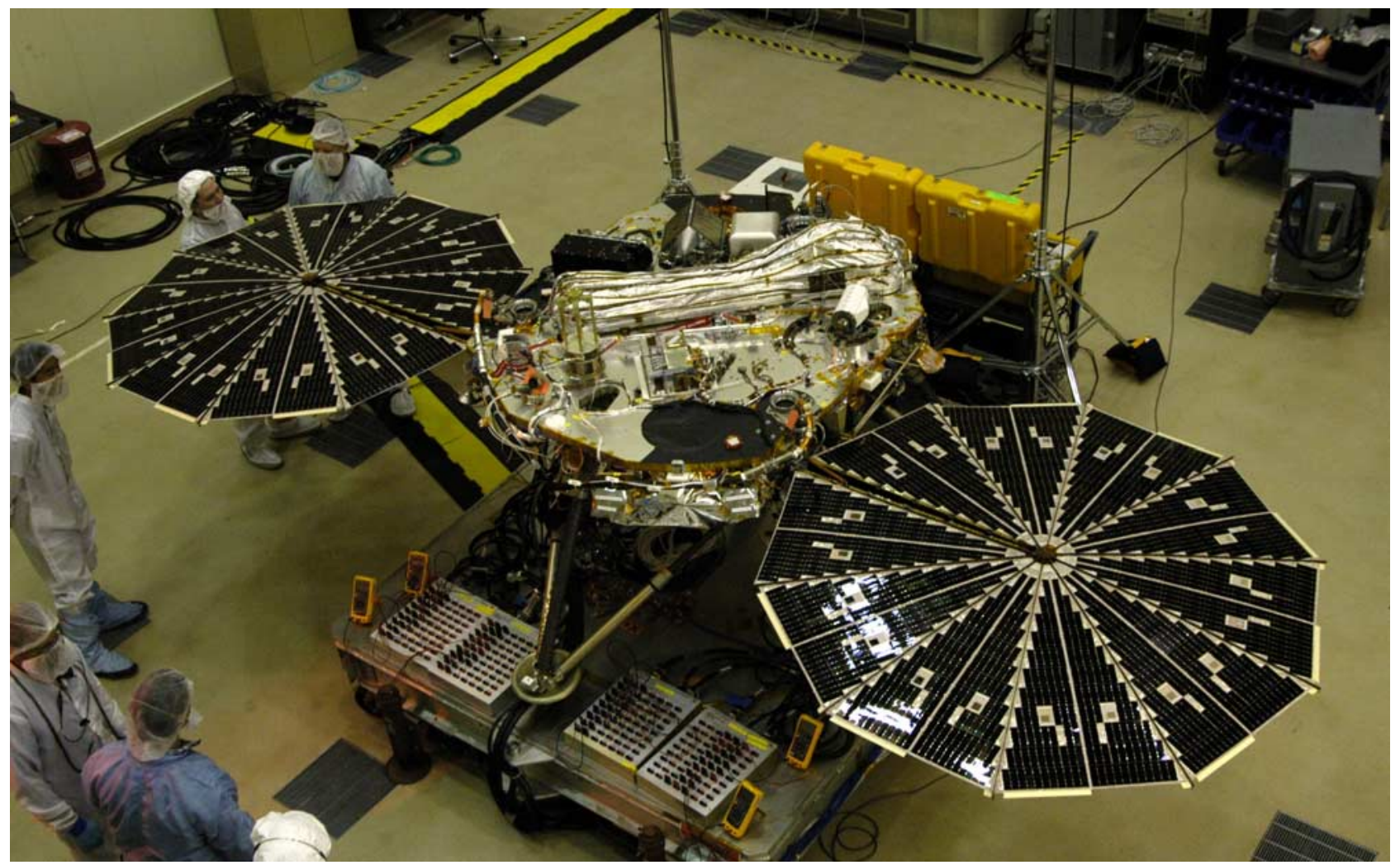

Figure 1. The spacecraft in its landed configuration during the assembly and test phase of the mission. It is undergoing a test of the solar panels in the Lockheed Martin clean room. The Robotic Arm crosses the middle of the deck under the biobarrier.

heritage of the 2001 Mars lander, even though sister boards and identical systems were flying on Odyssey, or had been successfully used on Genesis, Stardust, or Mars Global Surveyor. Many subsystems had flown to Mars on the twin spacecraft Mars Polar Lander and Mars Climate Orbiter. Clearly, the landing systems on Mars Polar Lander required a detailed reengineering, but what about the other systems that had performed nominally, in some cases for years beyond their design limits?

[41] These components had all been used on orbiters that are able to maintain a stable thermal and power environment for their avionic boxes. A lander, on the other hand, is subjected to a more stressful environment with a broad range of temperature extremes. Thus, the components had never been tested in space at the temperatures and pressures expected for the Phoenix lander. The team struggled for months to evaluate and in some cases test the components and electrical parts throughout the expected Mars conditions. At the completion of this activity over 800 actions and concerns had been identified. The step-by-step correction of these tabulated action items built reliability back into the hardware developed during the faster-better-cheaper era. The lander is shown in Figure 1 during the assembly and testing phase of the mission.

[42] Despite the reliability of the hardware, EDL carries the largest risk of the mission. Following the loss of MPL during this crucial phase of the mission, special attention has been given to EDL through the formation of a joint JPL-LM EDL working group formed early in the project.
Part of this phase is the selection of a landing site that meets the safety standards of the engineering team as well as the science desires. On the basis of lessons learned from the MPL loss, Phoenix has the requirement to maintain constant communications to either the MRO or Odyssey orbiter during EDL; the status of the lander will be continuously monitored and compared with predictions.

\section{Scientific Objectives}

\subsection{Level 1 Requirements}

[43] The Phoenix mission first and foremost is an in situ investigation of the near surface ice discovered by Odyssey's GRS team. The choice of landing site is guided by their ice maps of the northern region, bounded by latitudes chosen to maximize solar energy and communication opportunities with the orbiters. Since the spacecraft is stationary after landing, the exploration phase of the mission is to uncover layers beneath the surface down to an ice boundary that is expected to be extremely hard and impenetrable.

[44] There is no guarantee that Phoenix will land on icy soil because the Odyssey footprint $(>500 \mathrm{~km})$ only provides an average value over this large area. For this reason, there are no ice requirements in our top level project documents only to dig to $50 \mathrm{~cm}$ or an impenetrable layer. However, the geomorphology in the northern plains strongly suggests a buried ice table [Mellon et al., 2008b]. See Table 3 for actual Level 1 requirements; they are divided into four sets of objectives such that associated science theme groups develop procedures to meet these goals. 
Table 3. Level 1 Requirements for Phoenix

\begin{tabular}{|c|c|}
\hline Theme & Requirement \\
\hline Present climate & $\begin{array}{l}\text { Determine the daily and seasonal variations in weather at the landing site. Weather is defined as } \\
\text { temperature, dust opacity, pressure, and humidity. } \\
\text { Determine the exchange of water vapor with the subsurface, including } \mathrm{D} / \mathrm{H} \text { ratios of the atmosphere and } \\
\text { surface samples, near-surface air temperature and surface temperature, and atmospheric water vapor } \\
\text { abundance throughout the mission. } \\
\text { Determine the bulk atmospheric composition, including isotopic ratios of } 3 \text { major elemental components } \\
\mathrm{C}, \mathrm{O} \text {, and Ar. } \\
\text { Measure the acceleration during EDL to constrain models of the atmospheric density profile. }\end{array}$ \\
\hline Digging and sampling & $\begin{array}{l}\text { Dig a trench to an impenetrable layer, or } 50 \mathrm{~cm} \text {, whichever is reached first. } \\
\text { Gather samples from the surface down to the trench bottom and transport and deliver these samples to } \\
\text { instruments on the deck. }\end{array}$ \\
\hline $\begin{array}{l}\text { Geomorphology and } \\
\text { physical properties }\end{array}$ & $\begin{array}{l}\text { Image regional and local landforms and surface deposits and place observations in the context of orbital data. } \\
\text { Identify any subsurface layering and distribution of subsurface water ice. } \\
\text { Determine subsurface mechanical properties as a function of depth and correlate with visual, textural, } \\
\text { chemical, and mineralogical data. } \\
\text { Image data shall be used to determine the morphology, topography, reflectance, and photometric behavior of } \\
\text { excavated materials. } \\
\text { Characterize surface and subsurface physical properties (e.g., temperature, electrical and thermal conductivity, } \\
\text { grain morphologies, weathering and coatings). }\end{array}$ \\
\hline Chemistry and mineralogy & $\begin{array}{l}\text { Measure the concentration and gradient of elements and minerals in the surface and subsurface, } \\
\text { particularly organics, salts, hydrated minerals, sulfates, carbonates, oxidants, and other volatile-rich } \\
\text { substances, and correlate these with ice. } \\
\text { Verify the presence and identify the form of } \mathrm{H}_{2} \mathrm{O} \text { on the surface and within the subsurface and provide this } \\
\text { data for validation of models. }\end{array}$ \\
\hline Biological potential & $\begin{array}{l}\text { Measure the biological potential of the surface and subsurface environments by determining if liquid water has } \\
\text { been present, measuring compounds formed from the biogenic elements } \mathrm{C}, \mathrm{H}, \mathrm{N}, \mathrm{O}, \mathrm{P}, \mathrm{S} \text {, by measuring } \\
\text { the concentrations of biologically relevant ions including } \mathrm{K}, \mathrm{Ca}, \mathrm{Mg}, \mathrm{Na} \text {, and by assessing the } \\
\text { redox potential. }\end{array}$ \\
\hline
\end{tabular}

[45] Models of the transport of water into the polar regions predict that ice layers will form at a depth of several $\mathrm{cm}$ beneath the surface by virtue of diffusion of vapor through a porous soil down to a frost point where the temperatures are below $200 \mathrm{~K}$ [Mellon, 2003; Mellon et al., 2008a]. Seasonal breathing and diffusion of water vapor through the warmer surface layers, the active zone where ground temperatures are influenced by seasonal climate change, may lead over time to large deposits of ice beneath the surface. This process should be ubiquitous north of $60^{\circ}$, making it likely that Phoenix will find ice beneath the surface.

[46] Therefore, the primary goal is to study the history of the ice and its emplacement mechanisms [see Mellon and Jakosky, 1995]. History in this case means to discover whether the ice has ever warmed to the temperature where it melts to liquid water and alters the soil mineralogy and chemistry. Note that the atmospheric pressure at the landing site is greater than 6.4 mbar during the summer and is above the triple point for pure water of $6.1 \mathrm{mbar}$. Salty ice could melt at lower temperatures.

[47] A second scientific goal for the mission is to address the affect that subsurface ice has on the local geomorphology of the surface and any layering beneath the surface. Rock distributions, polygon boundaries, soil composition, and landforms will be evaluated to understand their creation processes. Evidence of meltwater features will be of great value to understanding the history of the area.

[48] Third, a complete scientific picture of the landing site requires understanding local climate and weather. Measuring humidity, pressure, temperature, opacity, and cloud properties using a sophisticated weather station throughout the summer season will factor into the description of the site.
[49] Finally and perhaps of greatest general interest, the question of the habitability of the icy soil is addressed. It is widely accepted that life must be scarce and well hidden on Mars, and the chance of landing on an enclave of microbial activity seems small given the lack of any biosignatures seen from orbit. However, there is the opportunity to evaluate the biological potential of the area. In other words, have conditions been acceptable in the past few million years to provide a habitat for microbes? Proving that liquid water has altered the site, that complex organic molecules are associated with the ice, and that energy sources exist would lead us to believe that the conditions are favorable for life in the northern plains. Searching for actual life would be the goal of another mission. The Phoenix mission is a stepping stone in this regard.

\subsection{Planetary Protection and Contamination Control}

[50] Planetary protection is an important consideration for missions that are exploring a potentially habitable zone; Phoenix is rated category IVc, meaning that the parts of the spacecraft that touch ice must be sterilized. Overall the spacecraft and instruments are treated to the standard alcohol wipe and class 100,000 clean room assembly conditions (clean rooms are specified by the number of particles greater than $0.5 \mu \mathrm{m}$ found in a cubic foot of air). Surfaces are swabbed and bacterial surface counts are routinely conducted to ensure that the live spores are kept at less than 300 spores/sq. m. The total surface burden of spores is calculated on the basis of the counts and surface area; Phoenix has easily met and exceeded the standards required for this mission.

[51] The Robotic Arm touches soil that has the potential of being habitable; therefore, sterilization and protection within a biobarrier are required. After final assembly, 
including sealing the biobarrier, the RA assembly is heated using the standard formula of $50 \mathrm{~h}$ at $125^{\circ} \mathrm{C}$; a process called dry heat microbial reduction. The biobarrier will not be opened until the spacecraft is safely on Mars.

\subsection{Archiving of Data in PDS}

[52] The level 1 document requires archiving of all data within the Planetary Data System in a timely fashion. The Phoenix archiving working group responsible for archiving all raw data and data products is led by R. E. Arvidson, who hosts a node of the PDS at Washington University in St. Louis. Each instrument team is represented in this working group and all data formats are documented and tested in trial archival runs.

[53] The agreement is to archive all imaging data within 6 months and all data of any sort within 1 year of end of mission. Naturally, high-level data products take considerably longer to create than raw data and require a final version of both calibration reports and laboratory characterization and cataloging support data.

\section{Measurements to Meet the Objectives}

\subsection{Science Investigations}

[54] The Phoenix instrument suite can be divided into three major areas: imaging and digging; acquiring samples and on-deck analysis; and a weather station. The location of these instruments on the spacecraft deck is shown in the artist conception in Figure 2. A brief description of each instrument will be given here with a reference to the instrument paper that provides an in-depth examination of the requirements, design approach, calibration, and operation of the instrument.

\subsubsection{Imaging and Digging}

[55] The imaging function is accomplished using the panoramic SSI camera on a mast that peers from a $2-\mathrm{m}$ vantage point overlooking the digging area. With two "eyes" it has the capability of providing a digital elevation model of the local surface and any modifications made to the surface. The design of the SSI is based on the Imager for Mars Pathfinder (IMP [Smith et al.,1997]) and the MPL SSI [Smith et al., 2001], but it has been enhanced to four times the resolving power by using the MER CCD detector package. Each "eye" has a one megapixel capacity and the ability to create a complete panorama using a subset of 13 geological filters that span the spectral range from 440 to 1000 nm. M. T. Lemmon et al. (The Phoenix Surface Stereo Imager Investigation, manuscript in preparation, 2008) describe the imager, its capabilities, and the calibration.

[56] Responsivity can drift during the long cruise and it is important to periodically image a calibration target on the spacecraft deck. Leer et al. [2008] describe a set of calibration targets that are positioned in three locations on the deck. Each target consists of colored sweep magnets that inhibit accumulation of magnetic dust on their surfaces. In addition, special magnetic targets are included to assess the magnetic properties of the windborne dust.

[57] SSI provides the database needed to operate the Robotic Arm (RA [Bonitz et al., 2008]) with its scoop designed to dig a trench, create a tailings pile, place the Thermal and Electrical Conductivity Probe (TECP [Zent et al., 2008]), and provide samples to the on-deck instruments.

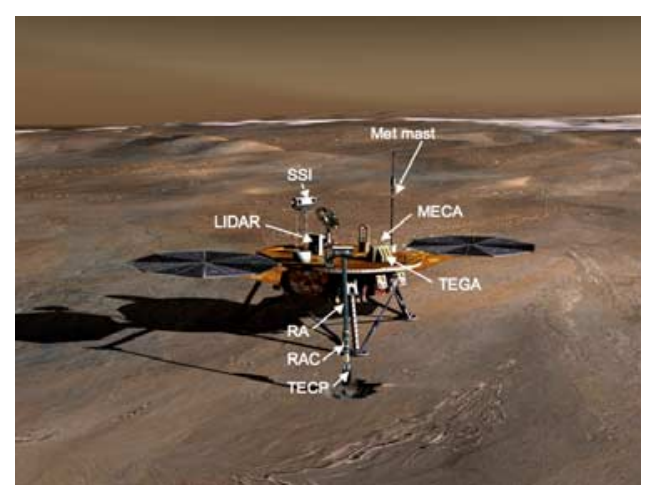

Figure 2. An artist conception of the spacecraft with the science instruments identified (NASA/JPL/C. Waste).

The RA is $2.3 \mathrm{~m}$ long and operates from a platform on the deck that serves as a shoulder joint: full azimuth and elevation motions are commandable. Halfway down the length of the RA is an elbow joint and near the end a wrist joint that controls the scoop. For close viewing of the trench and its features as well as the material inside the scoop, a robotic arm camera (RAC [Keller et al., 2008]) is fastened to the wrist of the RA. To complete the instrumentation associated with digging is the TECP fastened to the scoop joint in such a way that when the scoop is retracted the TECP tines are aligned with the arm and can be positioned to measure the thermal and electrical conductivity of the soil [Zent et al., 2008].

[58] The combination of the SSI, the RA, the RAC, and the TECP is a powerful package for examining the geological and physical properties of the local surface, including the presence of near-surface ice. As the science team becomes familiar with the various surface components, they will devise a plan to select samples for further chemical and mineralogical analysis. Some of the surface materials may have a compressive strength that makes sampling difficult. Indurated and ice-cemented soils can be scraped with a tungsten-carbide scraper on the bottom of the scoop, samples can be gathered from the scrapings. Solid ice, on the other hand, may be even stronger and a rasp is built into the rear of the scoop and powered by a small motor. This tool easily bores into even the hardest ice, throwing chips into the back of the scoop. From there the chips are transferred to the front surfaces and delivered to the Thermal and Evolved Gas Analyzer (TEGA) instrument, the only instrument designed to accept ice.

\subsubsection{Sample Acquisition and Analysis}

[59] Once the science team has agreed to acquire a sample from a feature on the surface or in a trench dug by the RA, then a series of operations takes place. First the surface is prepared so that cross contamination from material falling from the trench walls cannot easily get into the sample. Then RAC images are taken during the scooping operation and images of the sample in the scoop are taken in full color using the RAC LED lamps [Keller et al., 2008]. The RA is maneuvered so that the sample is ready to be poured into the receiving instrument and more RAC images are obtained as well as SSI images. After the pour, RAC images of the receiving port are taken to document the delivery. The TEGA instrument can also return a sample-received signal. 
[60] A sophisticated set of science instruments is attached to the deck and each has ports to receive samples from the arm. The first instrument to be described is TEGA. TEGA is based on the MPL instrument [Boynton et al., 2001]; however, the tunable diode laser has been replaced with a mass spectrometer to measure the composition of the evolved gases.

\subsubsection{TEGA}

[61] The TEGA (W. V. Boynton et al., The Thermal and Evolved Gas Analyzer on the Phoenix Mars Lander, manuscript in preparation, 2008) has three major functions. First is sample collection, that initiates when a double door over one of eight ovens is opened. A sample can now be dropped from the RA scoop onto a screen with 1-mm mesh. Under the screen is a trough that slopes toward a small opening directly above the receiving part of the tiny oven. To ensure that a significant portion of the sample will drop through the screen and enter the oven, a shaker vibrates the structure and tamps particles through the small opening. The final step is to mechanically seal the oven.

[62] Once the oven is sealed with its sample inside, the sample analysis takes place during several days. A low temperature ramp to $35^{\circ} \mathrm{C}$ melts any ice and drives its water vapor out of the sample. This step determines the composition of an ice-soil mixture, particularly the fraction of soil in the ice. On the second day the oven is ramped up to a higher temperature and a small portion of the gases are flowed into the mass spectrometer called the Evolved Gas Analyzer (EGA). The final phases take place in two redundant parts on separate days. A thermal sweep slowly raises temperatures to nearly $1000^{\circ} \mathrm{C}$ and measures the gases in the EGA. The repeat cycle does the same sweep again but now the volatiles are gone and the sweep serves as a baseline to conduct differential scanning calorimetric (DSC) analysis by differencing the power scans from the 2 days.

[63] The signatures obtained from DSC are diagnostic of the mineral content of the sample. The thermal sweep is designed so that the heater power is controlled to maintain a constant temperature change rate, typically $20^{\circ} \mathrm{C} / \mathrm{min}$. Any phase changes in the sample are recorded as deviations on the power profile. The area under the deviation is proportional to the heat of enthalpy in the transition. The temperature and derived heat of enthalpy allow the scientists to distinguish iron carbonate from calcium carbonate, for instance, and can accurately provide the composition of a sample in terms of the altered minerals. TEGA is not sensitive to refractory minerals.

[64] Besides the collector and the oven, the EGA is the third functional part of the TEGA. Its ionization chamber receives a small portion of the gas forced out from the heated oven by a carrier gas. One or two electrons are stripped off and the resulting ions are accelerated into the mass spectrometer chamber using a strong electric field. A powerful sweep magnet then directs the ions into the detectors according to their mass-charge ratio. The EGA provides the counts/s for a mass range from 2 to $140 \mathrm{Da}$ and allows the detection of isotopic fractionations.

[65] The most likely gases to evolve form the heated samples are carbon dioxide and water vapor. The TEGA can also be used to measure the composition of atmospheric gases by shutting the valves from the ovens and opening an inlet valve to the atmosphere.

[66] The combination of the DCS measurements and the EGA measurement of the evolved gases gives TEGA the power to measure the ice and mineral content of the samples as well as isotopic signatures [Fisher et al., 2008]. Moreover, the TEGA instrument is also attempting to measure the concentration of complex organic molecules in the soil. The TEGA is assembled under class 100 conditions and the sample collection doors are sealed after assembly by a motorized shield that is only removed after landing. This shield protects TEGA from the organic materials that inevitably inhabit a spacecraft interior after the vibrations of launch and the outgassing during cruise. The RA has been sterilized, but even dead microbes are contaminants.

[67] Despite best efforts there is likely to be a contamination signal measured in the TEGA cells. Distinguishing between terrestrial contamination and true Martian organic signals is achieved in two ways. First, a catalog of TEGA signatures has been established including greases, epoxies and electronic parts and fixtures. Second, an organic-free blank [Ming et al., 2008] is positioned inside the RA biobarrier and can be sampled using the same rasp system that is used to sample ice. This exercises the entire sampling chain as well as the collection surfaces in a TEGA cell. The organic signatures collected include the mass spectrum, the temperature at which the organic-rich gases are driven off, the DSC signal, and the depth of the sample beneath the surface. These clues are compared with a catalog of laboratory measurements of spacecraft materials, likely contaminates, and meteoritic organics. Signatures from Martian soil must be clearly distinguishable from those seen from the blank and the laboratory before any claims of Martian sources can be made.

\subsubsection{MECA}

[68] The MECA instrument has several parts corresponding to the meaning of the acronym: Microscopy, Electrochemistry, and Conductivity Analyzer. A black box on the spacecraft deck contains an optical microscope (OM [Hecht et al., 2008]) and four wet chemistry laboratory cells (WCL [Kounaves et al., 2008]); these receive surface samples from the scoop on the RA. The RA positions the TECP, part of MECA discussed above, into the soil for measurement of the thermal and electrical properties [Zent et al., 2008].

\subsubsection{WCL}

[69] For each of the four, single-use Wet Chemistry Labs (WCL), a two-sol experiment starts by heating its tank that holds $25 \mathrm{~mL}$ of frozen leaching solution. This solution is mainly water with very small amounts of dissolved salts used to calibrate the sensors. Once thawed, a valve is punctured allowing the solution to flow into the lower cell lined with sensors of various types; they immediately start monitoring the solution. After an equilibration time, a small crucible adds a mixture of salts to provide a second calibration point. After another equilibration period, the WCL is ready to accept the sample that has been collected in the scoop. The WCL extends a collection drawer that can receive about a 1-cc sample from the scoop. Upon retraction the drawer forms a seal and releases the sample into the cell. A stirring rod is then activated to mix the soil with the solution and the cell is heated to $5^{\circ} \mathrm{C}$ to ensure it will remain 
liquid during the analysis. The sensors are monitored for the remainder of the sol, measuring the dissolved ionic components and properties of the sample, until the WCL is shut down and the solution allowed to freeze.

[70] During the second sol the WCL experiment will determine the effect of adding an acid and also measure the sulfate in the sample. The analyses begin once the cell is thawed. A crucible containing an acid is added and the sensors monitored. Changes in the dissolved concentrations and other parameters will provide information about the sample's chemical and mineralogical composition. After a predetermined time, the sulfate titration analysis will begin by adding the first of three crucibles containing barium chloride. The barium will precipitate any sulfate that had dissolved from the sample into the solution. The barium remaining in solution is used to calculate the original sulfate concentration in the sample.

[71] This experiment duplicates the potential environment that results from warmer temperatures and melting of the upper ice layers. Evaporites quickly go into solution and an inventory of the salt content of the soil can be conducted. Many other chemical properties can be assessed such as acidity, metal content, and redox pairs; the many sensors are listed by Kounaves et al. [2008]. This powerful experiment when combined with the mineral assay from TEGA will allow the Phoenix team to profile the soil chemistry from the surface to a potential ice layer.

\subsubsection{OM and AFM}

[72] In the same box as the WCL is the OM that can accept 10 separate samples for microscopic examination. The sample collection stage extends a portion of the sample wheel out through a small port so that the RA can drop soil into the 6 collection bins that are exposed. The wheel consists of 69 such bins and can receive 10 samples throughout the life of the mission. Nine cells are reserved for calibration and special purposes.

[73] The sample stage rotates the sample bins $180^{\circ}$ so that the bins face along the horizontal direction. In this configuration, the wheel is driven away from the collection port toward the microscope station. Once the wheel nears the focal plane of the microscope it can both rotate and move through focus so that the microscope can examine the 6 bins. The microscope has $4 \mu \mathrm{m} /$ pixel resolution and the CCD detector is $256 \times 512$ pixels in size. The samples are lit by sets of LEDs positioned around the objective lens with a standard set of RGB colors. In addition, there is a UV LED to look for fluorescence in the sample.

[74] Once an interesting feature has been identified, the atomic force microscopy (AFM) can be used to zoom in for a closer look. The AFM has the potential for $100 \mathrm{~nm}$ resolving elements, giving it the ability to examine the surface texture of a grain of sand. A complete description of the AFM is provided by Hecht et al. [2008].

[75] Microscopy in combination with the mineral and chemical descriptions of the soil is a powerful tool to characterize the soil properties. The colors of the grains along with their size distributions may change with depth. The grain shapes are indicators of their history, for instance, angular freshly broken grains are weathering in place and have not been exposed to the actions of wind or moving water [Yen et al., 2005; Sullivan et al., 2005; Haskin et al., 2005].

\subsubsection{Weather Station (MET)}

[76] Monitoring polar weather is a major goal of the Phoenix mission. The Canadian Space Agency (CSA) has generously provided the weather station and contributed members to the science team to help operate the instruments and interpret the data.

\subsubsection{Pressure and Temperature}

[77] Fundamental to any weather station is the ability to measure the surface pressure and atmospheric temperature. As with previous landers, a data set of the decelerations measured during entry will be used to model the atmospheric structure above the landing site. The pressure sensor was chosen to be able to distinguish seasonal and diurnal variations as well as the low-pressure cores of dust devils [Taylor et al., 2008]. These measurements will be compared to the pressures measured at the two Viking sites and the Pathfinder site.

[78] Temperature is a more difficult measurement since the spacecraft can disturb the local thermal environment. A mast (built from MPL and Pathfinder heritage at JPL) was provided to the CSA team so that three thermocouple sensors could be vertically positioned above the deck. The lowest one is most heavily influenced by the deck temperature, but the upper two give us a chance to measure both the air temperature and its gradient [Taylor et al., 2008].

\subsubsection{Wind}

[79] Even a coarse measurement of wind is important to Phoenix. First, sample delivery is influenced by winds and strong winds can prevent the transfer of a sample into a collection port. Second, a correlation of wind direction with humidity helps us understand the transport of water vapor across our site. To measure winds, the top of the mast holds a telltale built a thin Kapton tube and Kevlar fibers. The SSI camera images the telltale and can tell both the direction and velocity of the wind through a sequence of images. The flight unit has undergone extensive calibration in a specially constructed Mars-like wind tunnel at the U. Aarhus in Denmark [Gunnlaugsson et al., 2008].

\subsubsection{Lidar}

[80] To meet our goal of measuring the properties of the local boundary layer, CSA contracted MDA, assisted by Optech, to build a lidar to probe the lower $10 \mathrm{~km}$ of the atmosphere [Whiteway et al., 2008; Tyler et al., 2008]. The lidar has a 1,064-nm laser that is split and frequency doubled on one leg to give a second 532-nm beam. The two beams are pulsed upward through layers of dust and ice particles and the reflections are measured through two separate systems. The 1,064-nm reflections are collected in a silicon photodiode and read out through an analog-to-digital converter while the green channel is processed through a photoncounting circuit with a discriminator noise reduction system.

[81] An engineering model has been thoroughly tested under field conditions; cloud height, thickness, and composition are distinguishable and can be tracked diurnally and seasonally. The changing height to the top of the boundary layer and the underlying turbulence are new areas of study for Mars. Predictions for what signals that the lidar may find from clouds and dust on Mars are given by Pathak et al. [2008].

\subsubsection{Atmospheric Imaging}

[82] The SSI plays an important role in atmospheric science. Its solar filters are used to measure the dust opacity 
at several wavelengths across the spectrum. Sky radiance measurements are used to estimate the particle size distribution and albedo of the particles as was done for Pathfinder [Tomasko et al., 1999]. Dust devils can be imaged and their sizes deduced to support the boundary layer studies [Ferri et al., 2003]. Finally, there is hope that green laser light reflecting off the clouds during the darkest times of the mission can be detected by SSI.

\subsubsection{Humidity}

[83] Phoenix has two ways of measuring the humidity of the atmosphere. TEGA has a port that samples the atmosphere and can measure the water vapor content. Not only can it measure the major constituents of the atmosphere, but by gettering the $\mathrm{CO}_{2}$, it can improve the accuracy for the minor constituents up to the instrument limit of $140 \mathrm{Da}$.

[84] The second method is through the TECP that has a small humidity sensor embedded inside. This movable sensor can reach from trench bottom, where it also measures the surface temperature, to a height of about $3 \mathrm{~m}$. A set of vertical measurements using the same sensor for the humidity gradient removes some of the tricky calibration problems that come with trying to match different sensors over a wide range of temperatures.

\subsection{Interoperability Between Instruments}

[85] Most of the instruments conduct their measurements without any interactions with other instruments once they have their samples. The MET station is a stand-alone weather station except for the telltale that must be imaged. However, there is a major interaction between instruments developed at widely separated institutions when it comes to sample acquisition and delivery.

\subsubsection{Sample Delivery Chain}

[86] The RA cannot be operated without a digital elevation model of the digging area constructed with SSI images. Samples cannot be verified in the scoop unless the RAC looks inside. The various instruments need to know when to open their collection ports and when to close them, with high probability that a documented sample has been input properly. Icy soils are particularly difficult to sample and many steps are required to produce an acceptable sample. All these interactions between instruments require practice; this is what the Payload Interoperability Testbed (PIT) has been designed to accomplish.

[87] The PIT consists of an adjustable spacecraft structure, a mockup to hold the deck at the right height and tilt, and a set of engineering model instruments as flight-like as possible. The instruments are driven and controlled by a full spacecraft simulator that can run actual flight software and simulate a flight-like interface. The test lab can be run from the UA or either JPL or LM. Much of the instrument verification and validation testing is done at this facility and all of the surface operational testing is done here. The model spacecraft is surrounded by a Mars stage set to give some sense of reality to the tests; the science team is only allowed to see the set through the eyes of the cameras. A bin filled with soil layers is positioned for the RA to practice digging trenches and gathering samples.

\subsubsection{Sampling Ultracold Icy Soil}

[88] Because the goal on Mars is to sample the icy soil layer, we practice with ices cooled to $-80 \mathrm{C}$ and use the RASP to gather samples. The RASP is a tungsten-carbide rasp that extends $6 \mathrm{~mm}$ below the back of the scoop and has been designed to provide samples of even the hardest icesoil combination at low temperature. The RASP only needs about $30 \mathrm{~s}$ to dig up chips, but it takes many runs to collect enough for TEGA, the only instrument that requires the icy soil. A Mars chamber has been designed at Honeybee Robotics for testing the gathering and delivering of samples. This may be the final sample delivered and holds the potential for solving the question of how the ice layers and the atmosphere interact. Bonitz et al. [2008] describe this system.

\section{Mission}

\subsection{Mission Success}

[89] The Phoenix mission began with a Delta 2 launch from Cape Canaveral on 4 August 2007. The trajectory includes six planned course maneuvers designed to put Phoenix on an entry path to land in the northern plains on 25 May 2008. A mission description is given by Guinn et al. [2008].

[90] An important part of the Level 1 agreement with NASA is the description of full and minimum mission success. These lists of accomplishments become a scorecard for the mission as we progress through our first 90 sols. Naturally, a safe landing is at the top of the list. Second, we require a panoramic view of the landing site in true color. This leads to digging from the surface to an impenetrable layer and providing samples to our TEGA and MECA instruments at three depths. Finally, the list ends with the temperature and pressure measurements throughout the mission. Full mission success criteria as stated in the Level 1 requirements document are as follows: (1) Land successfully on the surface of Mars and achieve a power-safe state. (2) Acquire a true color (RGB), $360^{\circ}$ panorama of the landing site. (3) Obtain calibrated optical spectra of at least three locations that include both rocks and soil. (4) Provide temperature and pressure measurements throughout landed surface operations at a frequency that determines key atmospheric properties. (5) Provide samples of the surface soil as well as samples from two depths beneath the surface to both TEGA and MECA. (6) Use TEGA to analyze at least three soil samples to create a profile of $\mathrm{H}_{2} \mathrm{O}$ (in the form of hydrated minerals, adsorbed water, or possibly ice at the deepest level) and mineral abundances near the surface, and it shall also analyze an atmospheric sample in its mass spectrometer. (7) Use MECA to analyze the wet chemistry of at least three soil samples, and it shall also analyze three additional samples in its microscopy station. (8) Document all nine nonatmospheric samples and their collection locations (before and after sampling) with images.

[91] Since a successful mission could be envisioned even with the loss of either TEGA or MECA, minimum mission success reflects this unfortunate possibility. The same is true of the SSI versus the RAC and the loss of one of the cameras could still lead to limited mission success. The single point failure of the RA, however, cannot be tolerated because then we could not dig beneath the surface or provide samples to our instruments. For this reason, special attention was paid to the development of the RA; it is mission critical. Minimum success criteria in the level 1 
Table 4. Entry, Descent, and Landing Timeline ${ }^{a}$

\begin{tabular}{|c|c|c|c|c|}
\hline Time & Configuration & Altitude & Velocity & Comment \\
\hline E-5 $\min$ & cruise stage separation & & $20 \mathrm{~km} / \mathrm{h}$ & \\
\hline $\mathrm{L}-528 \mathrm{~s}$ & entry & $125 \mathrm{~km}$ & & \\
\hline L-146 s & parachute deploy & $9 \mathrm{~km}$ & Mach 1.3 & \\
\hline L-131 s & heat shield jettison & $7.4 \mathrm{~km}$ & $103 \mathrm{~m} / \mathrm{s}$ & \\
\hline $\mathrm{L}-121 \mathrm{~s}$ & leg deployment & & & radar activated \\
\hline L-32 s & lander separation & $0.93 \mathrm{~km}$ & & \\
\hline $\mathrm{L}-10 \mathrm{~s}$ & constant velocity & $12 \mathrm{~m}$ & $5.5 \mathrm{~m} / \mathrm{s}$ & \\
\hline $\mathrm{L}-0 \mathrm{~s}$ & touchdown & $0 \mathrm{~m}$ & $2.4 \mathrm{~m} / \mathrm{s}$ & \\
\hline $\mathrm{L}+15 \mathrm{~min}$ & solar array deploy & & & $\begin{array}{l}\text { deploy SSI, MET mast, and } \\
\text { biobarrier }\end{array}$ \\
\hline
\end{tabular}

${ }^{a}$ Entry (E) is at 25 May 20082331 UTC, but landing (L) is less determinate because of uncertainties in various transition times.

document are as follows: (1) Land successfully on the surface of Mars and achieve a power-safe state. (2) Acquire a partial $120^{\circ}$ monochromatic panorama of the landing site. (3) Provide samples of the surface soil as well as samples from one depth beneath the surface to either TEGA or MECA wet chemistry. (4) If TEGA, it shall analyze at least two soil samples to create a profile of $\mathrm{H}_{2} \mathrm{O}$ (in the form of hydrated minerals, adsorbed water, or possibly ice at the deepest level) and mineral abundances near the surface, and it shall also analyze an atmospheric sample in its mass spectrometer. (5) If MECA, it shall analyze the wet chemistry of two soil samples. (6) Document all nonatmospheric samples and their collection locations with images.

\subsection{EDL Activities}

[92] The MER rovers landed in January 2004 about 5 months after the start of the Phoenix phase B; the telemetry returned during the descent showed oscillations of the probe well beyond what had been predicted. It was clear that despite the two safe landings, the engineering data showed that risk of failure was still higher than desired. The impact on the Phoenix project was to bring the JPL experts into the EDL working group and rework the entire EDL sequence to reduce the risk in the off-nominal cases. NASA provided additional funds specifically to incorporate the knowledge gained from the rovers and increase the chances of a successful landing. The failure to land safely, depending on the cause, could have a devastating effect on future landed programs.

[93] Phoenix can land safely if the conditions allow the spacecraft to stay within its defined entry corridor. However, if it drifts away from the nominal parameters, there is a steep rise in the chance of failure. Graceful degradation is the desired situation and it is difficult to achieve for Phoenix. Therefore, the working group has spent several years finding the best set of parameters such as the entry angle, the atmospheric properties on the day of landing [Michaels and Rafkin, 2008], the speed at which the parachute is released, and the transition to powered descent (see EDL timeline in Table 4). In addition, the rock distribution and ground slopes determine the final touchdown success rate. Thousands of Monte Carlo calculations, each with a randomly selected set of incoming trajectory, atmospheric, and landing site parameters, are used to predict the percentage of successful landings.

[94] The importance of the EDL working group to the success of Phoenix cannot be overstated. Remember that MPL, the sister ship, failed to land safely for unknown reasons. Within our proposal plan, we agreed to accept all reasonable probing and testing of the spacecraft in phase B. This included a hot fire test of the propulsion system to verify that vibrational modes induced into the spacecraft were within the design limits. These activities were all successfully completed in phase B, but the EDL team bored relentlessly into the inner workings of every component involved in EDL and found that there were other serious problems that needed correction.

[95] The common understanding is that MPL failed when the landing legs deployed, jiggling the touchdown sensors and causing the spacecraft to turn off the thrusters about $40 \mathrm{~m}$ above the surface. This indeed could have happened and the irony is that the failure mode is easily removed by not listening to the sensors until well after the legs are deployed. However, the EDL team found many other potentially fatal flaws: the separation connectors that electrically disconnect the cruise stage require substantially greater separation force at cold temperatures; the cruise stage follows the entry module and can recontact it during hypersonic braking; there were excessive parachute loads on the structure and the chute needed to be redesigned; and, finally, the landing radar is the Achilles heel of the spacecraft with a multitude of failure modes (see Figure 3).

[96] After analysis of the first radar drop test in January 2006, numerous problems were identified as serious enough to require a special "tiger" team to work the issues. Dara Sabahi (JPL) led this team consisting of both JPL and LM engineers. A detailed description of the detective work that the team conducted and the fixes proposed is beyond the scope of this paper. Suffice it to say that two more drop tests were performed leading to a satisfactory test result in October 2006. Even so, that was not the end of the radar troubles and final disposition of all the action items and concerns followed the project all the way to Cape Canaveral.

[97] Prior to launch a series of review boards wrestled with the issue of whether Phoenix had indeed found and corrected all the EDL failure modes just in time for launch or perhaps there were one or more that had yet to be discovered. Naturally, there is no way to answer this question; the EDL team has put into place corrective actions for all known failure modes. If others exist, they must be considered as residual risk; the unknown problems now represent the largest risk to safe landing.

\subsection{Landing Site Selection}

[98] The ultimate goal of EDL is safely landing on the surface. The Phoenix clearance for rocks is $35 \mathrm{~cm}$ under the 


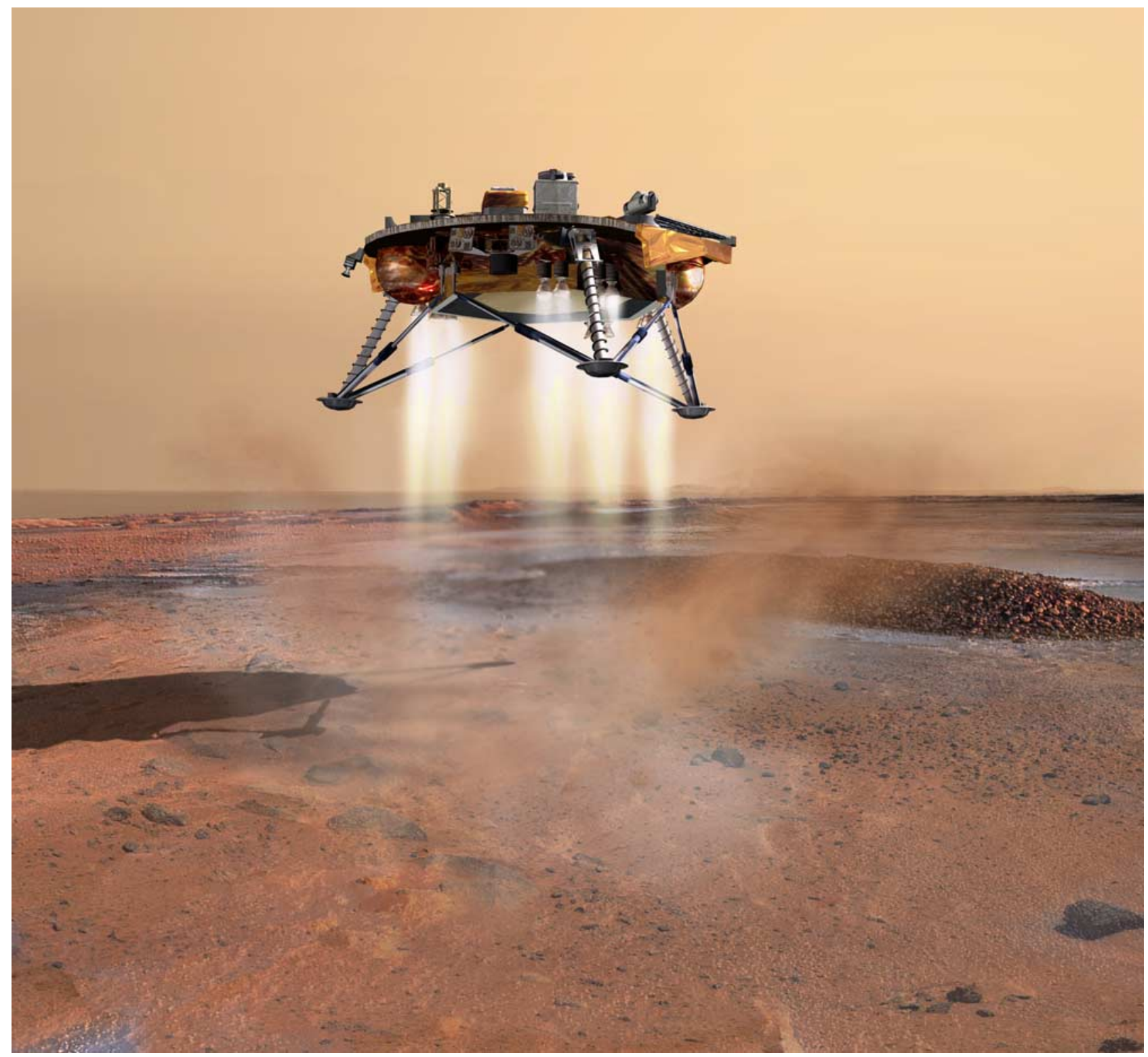

Figure 3. Artist's conception of Phoenix during the last minute of the propulsion phase just before landing on the Martian surface (NASA/JPL/C. Waste).

lander body and $50 \mathrm{~cm}$ under the solar panels, assuming a horizontal surface. Obviously, a landing location that contains a high concentration of large rocks or steep slopes is unacceptable. Considerable effort through the Landing Site Working Group led by Raymond E. Arvidson enabled selection of a compromise site providing safety from rocks and reasonable depth to ice.

[99] Observations were requested from Odyssey and MRO instrument teams in four regions labeled $\mathrm{A}-\mathrm{D}$; ground based radar scans were also analyzed [Gunnarsdottir et al., 2008]. The regions were defined by latitudinal boundaries at $65^{\circ} \mathrm{N}$ and $72^{\circ} \mathrm{N}$ that balanced the engineering needs for solar power and communications with the probability of landing on an icy subsurface. The regions were widely distributed in longitude to allow for regional differences to be examined. After an exhaustive comparison of the pros and cons associated with each site [Seelos et al.,
2008; T. Siili et al., Mesoscale modeling of the phoenix landing locations, manuscript in preparation, 2008], region $\mathrm{B}$ was determined to be the favorite candidate in the summer of 2006. But the first images from HiRISE, the highresolution camera on $\mathrm{MRO}$, in October 2006 changed everything.

[100] The preferred location in region B has now been shown to harbor clusters of boulders typically associated with ancient crater rims. It proved impossible to find large areas that did not contain several of these clusters. The search began for a safe site using the highest-resolution images ever obtained from Martian orbit [Kirk et al., 2008]. Eventually, a safe location was identified in region D and all resources were focused on this site: a complete description of the landing site is given by Arvidson et al. [2008] and the rock population is described by Golombek et al. [2008]. The Phoenix landing site is north of Alba Patera at $68^{\circ} \mathrm{N}$ and 
$233^{\circ} \mathrm{E}$ in a shallow valley dubbed "Green Valley" by the team because green was used to represent a low distribution of large rocks.

\subsection{Surface Operations Plan}

[101] The polar environment sets strict limits on operations. Phoenix is solar powered and the RA and deck instruments draw considerable power. All sampling and analysis is planned to be completed within the first 3 months of the mission, before the days become short. This desire forces a tight schedule with a detailed strategic plan and 1-day tactical adjustments. In addition, the team will be on Mars time $(1 \mathrm{sol}=24 \mathrm{~h} 40 \mathrm{~m})$ for the first 3 months.

[102] Activities shortly after landing day on 25 May 2008 at about 1638 local time, will be controlled from JPL and are devoted to deploying the solar arrays, extending the SSI mast, releasing the MET mast, and opening the biobarrier. A small number of SSI images will be taken of the spacecraft and surface, largely to verify deployments. All available downlinks will be used to gather data needed to assess the health of the spacecraft so that the science activities can begin. Once the spacecraft is power positive, has two-way communications, and is thermally stable, then control is transferred to the UA Science Operations Center in Tucson.

[103] The first week of the mission is devoted to characterization of all of the instruments and of the spacecraft. The RA will be deployed and tested throughout its range of motion. The effects of the thruster plumes on the digging area will be assessed [Plemmons et al., 2008]. The final step for characterization is to deliver a surface sample to the TEGA instrument. This signifies the beginning of the science operations phase of the mission.

[104] Operations for Phoenix follow a routine in the sense that without mobility the daily task is providing samples to the instruments on the deck and taking weather measurements. Cycles are defined that start with digging to a layer of interest, then sampling the layer for delivery. Each sample is carefully documented with images from the RAC and SSI. The sample is delivered to the cell of interest: TEGA, MECA WCL, or MECA OM. Finally, several days are devoted to running the sequences that analyze the sample; then the process starts over again.

[105] Strategic planning allows preparations to be made ahead of time so that the 1-day tactical plan meets its schedules; a detailed timeline is outlined by Bass and Talley [2008]. After the collection of data from the 8 TEGA cells, 4 WCL cells and $10 \mathrm{OM}$ sets, then the mission can return to Earth time operations and Phoenix becomes a weather station monitoring conditions as summer ends. Tamppari et al. [2008] provide an a assessment of the expected atmospheric environment during the Phoenix landed seasons.

\section{Conclusions}

[106] Phoenix is targeted to an unexplored region of Mars where ice is known to exist in close proximity to the surface. Therefore, a fixed platform lander can conduct a range of science experiments using only a robotic arm and instruments on the deck that can assess the mineralogy, chemistry and microscopy of the soils and ice. The connection between the ice, the soil overburden, and the atmosphere is of prime importance to understanding how the ice was emplaced in the northern plains.

[107] Experiments conducted with the SSI and RAC using the RA and the TECP to probe the local soil provide the science team with the ability to understand the local geomorphology and the physical properties of the soil layers. The distribution of small rocks in the polygonal boundaries of the patterned ground will never be possible to determine from orbit. The depth to the ice layer(s) can only be modeled and the soil properties are now chosen to match locations thousands of kilometers away at previous landing sites. Phoenix will provide ground truth that can be applied throughout the northern polar region.

[108] The presence of near-surface ice and the knowledge that the obliquity is causing the climate to vary on millionyear cycles opens the question of the periodic presence of unfrozen water. On Earth, the signatures of liquid water in soil are seen in the minerals and salts that are products of the weathering of the igneous rocks in the vicinity. TEGA and MECA are sensitive to even small changes in these properties and may show a progression from the hyperarid surface to a periodically moist ice-soil boundary. Microscopic examination of these soils offers another method of verifying the conclusions reached from chemical and mineralogical analysis.

[109] Another goal is to describe the habitability of the northern plains in terms of the episodic presence of liquid water and the availability of the energy sources and the chemistry needed to support life. The chance of finding life itself is vanishingly small; there are no indications from any orbiting spacecraft that there is a preferred location conducive to life. In addition, conditions in the present era are too cold to allow liquid water near the surface. However, the discovery of complex organic molecules and usable energy sources would be a giant step forward in the search for life in our solar system.

[110] Finally, a major goal is to monitor weather from the surface of the polar region. In particular, the transport of water vapor and the properties of the boundary layer are most significant. A record of the surface pressure and temperature will augment the two Viking and the Pathfinder weather stations that have returned information from the Martian surface. The polar weather is known from orbit to be more dynamic than the equatorial and midlatitude locations experienced to date.

[111] The combination of results from the geomorphology, the soil profile and analysis of the soil properties, and the atmospheric measurements will be augmented by the regional observations from the orbiters. The goal is to begin to paint a complete picture of the Mars arctic region that can be combined with the renewed interest in polar research on Earth to the benefit of both disciplines.

[112] Acknowledgments. The Phoenix science team appreciates the immense effort put forth by the project team to prepare the spacecraft to meet the challenges of landing and operating on Mars. The project manager, B. Goldstein, has lived and breathed this project for 5 years and provided excellent leadership under difficult circumstances. The team at Lockheed Martin led by E. Sedivy, many of whom have worked for nearly a decade on this project before it became a Scout mission, have shown exceptional engineering skill at every level during the development and cruise. The UA group led by C. Shinohara has prepared a world-class operations center starting from an empty, rather decrepit building. E. Weiler, the NASA associate administrator, was our selection official in 2003 and now, after 
several management restructurings, returns to participate in the landed mission. He is especially acknowledged for believing that Phoenix can rise from the ashes.

\section{References}

Arvidson, R. E., et al. (2008), Mars Exploration Program 2007 Phoenix landing site selection and characteristics, J. Geophys. Res., 113, E00A03, doi:10.1029/2007JE003021.

Bass, D., and K. Talley (2008), Phoenix surface mission operations processes, J. Geophys. Res., 113, E00A06, doi:10.1029/2007JE003051.

Bonitz, R. G., et al. (2008), NASA Mars 2007 Phoenix Lander Robotic Arm and Icy Soil Acquisition Device, J. Geophys. Res., 113, E00A01, doi:10.1029/2007JE003030.

Boynton, W. V., et al. (2001), Thermal and Evolved Gas Analyzer: Part of the Mars Volatile and Climate Surveyor integrated payload, J. Geophys. Res., 106, 17,683-17,698, doi:10.1029/1999JE001153.

Boynton, W. V., et al. (2002), Distribution of hydrogen in the near surface of Mars: Evidence for subsurface ice deposits, Science, 297, 81-85, doi:10.1126/science.1073722.

Christensen, P. R. (2003), Formation of recent Martian gullies through melting of extensive water-rich snow deposits, Nature, 422, 45-48, doi:10.1038/nature 01436

Feldman, W. C., et al. (2002), Global distribution of neutrons from Mars: Results from Mars Odyssey, Science, 297, 75-78, doi:10.1126/ science. 1073541.

Ferri, A., P. H. Smith, M. Lemmon, and N. Renno (2003), Dust devils as observed by Mars Pathfinder, J. Geophys. Res., 108(E12), 5133 , doi:10.1029/2000JE001421.

Fisher, D., R. Novak, and M. Mumma (2008), D/H ratio during the northern polar summer and what the Phoenix mission might measure, J. Geophys. Res., 113, E00A15, doi:10.1029/2007JE002972.

Forget, F., R. M. Haberle, F. Montmessin, B. Levrard, and J. W. Head (2006a), Formation of glaciers on Mars by atmospheric precipitation at high obliquity, Science, 311, 368-371, doi:10.1126/science.1120335.

Forget, F., F. Montmessin, B. Levrard, R. M. Haberle, H. W. Hed, and J.-B. Madeleine (2006b), Ice caps, glaciers and gullies: The effect of obliquity on Martian climate, paper presented at Fourth International Conference on Mars Polar Science and Exploration, Lunar and Planet. Inst., Davos, Switzerland.

Golombek, M., et al. (2008), Size-frequency distributions of rocks on the northern plains of Mars with special reference to Phoenix landing surfaces, J. Geophys. Res., 113, E00A09, doi:10.1029/2007JE003065.

Guinn, J., M. Garcia, and K. Talley (2008), Mission design of the Phoenix Mars scout mission, J. Geophys. Res., doi:10.1029/2007JE003038, in press.

Gunnarsdottir, H. M., I. R. Linscott, J. L. Callas, M. D. Cousins, R. A Simpson, and G. L. Tyler (2008), Root-mean-square surface slopes of Phoenix landing sites with $75-\mathrm{cm}$ bistatic radar received by Mars Odyssey, J. Geophys. Res., 113, E00A02, doi:10.1029/2007JE003040.

Gunnlaugsson, H., et al. (2008), Telltale wind indicator for the Mars Phoenix lander, J. Geophys. Res., 113, E00A04, doi:10.1029/2007JE003008.

Haberle, R. M., C. P. McKay, J. Schaeffer, N. A. Cabrol, E. A. Grin, A. P. Zent, and R. Quinn (2001), On the possibility of liquid water on presentday Mars, J. Geophys. Res., 106, 23,317-23,326, doi:10.1029/ 2000JE001360.

Haskin, L. A., et al. (2005), Water alteration of rocks and soils on Mars at the Spirit rover site in Gusev crater, Nature, 436, 66-69, doi:10.1038/ nature 03640.

Head, J. W., et al. (2005), Tropical to mid-latitude snow and ice accumulation, flow and glaciation on Mars, Nature, 434, 346-351, doi:10.1038/ nature 03359 .

Hecht, M. H., et al. (2008), Microscopy capabilities of the Microscopy, Electrochemistry, and Conductivity Analyzer, J. Geophys. Res., doi:10.1029/2008JE003077, in press.

Keller, H. U., et al. (2008), Phoenix robotic arm camera, J. Geophys. Res., doi:10.1029/2007JE003044, in press.

Kirk, R., et al. (2008), Ultra-high resolution topographic mapping of Mars with MRO HiRISE stereo images: Meter-scale slopes of candidate Phoenix landing sites, J. Geophys. Res., doi:10.1029/2007JE003000, in press.

Kounaves, S. P., et al. (2008), The 2007 Phoenix Mars Scout Lander MECA Wet Chemistry Laboratory, J. Geophys. Res., doi:10.1029/ 2008JE003084, in press.

Laskar, J., M. Gastineau, F. Joutel, P. Robutel, B. Levrard, and A. Correia (2004), Long term evolution and chaotic diffusion of the insolation quantities of Mars, Icarus, 170, 343-364, doi:10.1016/j.icarus.2004.04.005.

Leer, K., et al. (2008), Magnetic properties experiments and the SSI calibration target onboard the Mars Phoenix 2007 lander: Design, calibration and science goals, J. Geophys. Res., doi:10.1029/2007JE003014, in press.
Levrard, B., F. Forget, F. Montmessin, and J. Laskar (2004), Recent icerich deposits formed at high latitudes on Mars by sublimation of unstable equatorial ice during low obliquity, Nature, 431, $1072-$ 1075, doi:10.1038/nature03055.

Malin, M. C., and K. S. Edgett (2000), Evidence for recent groundwater seepage and surface runoff on Mars, Science, 288, 2330-2335, doi:10.1126/science. 288.5475 .2330

Mellon, M. T. (2003), Theory of ground ice on Mars and implications to the neutron leakage flux, Lunar Planet. Sci., 34, Abstract 1916.

Mellon, M. T., and B. M. Jakosky (1995), The distribution and behavior of Martian ground ice during past and present epochs, J. Geophys. Res., 100, 11,781-11,799, doi:10.1029/95JE01027.

Mellon, M. T., W. V. Boynton, W. C. Feldman, J. L. Bandfield, T. N. Titus, D. A. Paige, A. Hock, N. E. Putzig, R. E. Arvidson, and H. G. Sizemore (2008a), A pre-landing assessment of the ice-table depth and ground-ice characteristics in Martian permafrost at the proposed Phoenix landing site, J. Geophys. Res., doi:10.1029/2007JE003067, in press.

Mellon, M. T., R. E. Arvidson, J. J. Marlow, R. J. Phillips, and E. Asphaug (2008b), Periglacial landforms at the Phoenix landing site and the northern plains of Mars, J. Geophys. Res., doi:10.1029/2007JE003039, in press.

Michaels, T., and S. C. R. Rafkin (2008), Meteorological predictions for candidate 2007 Phoenix Mars Lander sites using the Mars Regional Atmospheric Modeling System (MRAMS), J. Geophys. Res., 113, E00A07, doi:10.1029/2007JE003013.

Ming, D., et al. (2008), Mars 2007 Phoenix scout mission organic free blank (OFB): Method to distinguish Mars organics from terrestrial organics, J. Geophys. Res., doi:10.1029/2007JE003061, in press.

Mitrofanov, I., et al. (2002), Maps of subsurface hydrogen from high energy neutron detector, Mars Odyssey, Science, 297, 78-81, doi:10.1126/ science. 1073616 .

Pathak, J., D. V. Michelangeli, L. Komguem, J. Whiteway, and L. K Tamppari (2008), Simulating Martian boundary layer water ice clouds and the lidar measurements for the Phoenix mission, J. Geophys. Res., 113, E00A05, doi:10.1029/2007JE002967.

Plemmons, D., B. C. Clark, S. P. Kounaves, M. Mehta, L. L. Peach, N. O. Renno, L. Tamppari, and S. M. M. Young (2008), Effects of the 2007 Phoenix lander descent thruster plum on the Martian surface, J. Geophys. Res., 113, E00A11, doi:10.1029/2007JE003059.

Seelos, K., et al. (2008), Geomorphologic and mineralogic characterization of the northern plains of Mars at the Phoenix Mission candidate landing sites, J. Geophys. Res., 113, E00A13, doi:10.1029/2008JE003088.

Smith, P. H., et al. (1997), The imager for Mars Pathfinder experiment, J. Geophys. Res., 102, 4003-4025, doi:10.1029/96JE03568.

Smith, P. H., et al. (2001), The MVACS Surface Stereo Imager on Mars Polar Lander, J. Geophys. Res., 106, 17,589-17,607, doi:10.1029/ 1999JE001116.

Squyres, S. W., et al. (2004), In-situ evidence for an ancient aqueous environment at Meridiani Planum, Mars, Science, 306, 1709-1714, doi:10.1126/science. 1104559 .

Sullivan, R., et al. (2005), Aeolian processes at the Mars Exploration Rover Meridiani Planum landing site, Nature, 436, 58-61, doi:10.1038 nature 03641.

Tamppari, L. K., et al. (2008), Atmospheric environment expected for the Phoenix landed season and location, J. Geophys. Res., doi:10.1029/ 2007JE003034, in press.

Taylor, P. A., D. C. Catling, M. Daly, C. S. Dickinson, H. P. Gunnlaugsson, A.-M. Harri, and C. F. Lange (2008), Temperature, pressure, and wind instrumentation in the Phoenix meteorological package, J. Geophys. Res., 113, E00A10, doi:10.1029/2007JE003015.

Tomasko, M. G., L. R. Doose, M. Lemmon, P. H. Smith, and E. Wegryn (1999), Properties of dust in the Martian atmosphere from the imager on Mars Pathfinder, J. Geophys. Res., 104, 8987-9007, doi:10.1029/ 1998JE900016.

Tyler, D., J. R. Barnes, and E. D. Skyllingstad (2008), Mesoscale and LES model studies of the Martian atmosphere in support of Phoenix, J. Geophys. Res., 113, E00A12, doi:10.1029/2007JE003012.

Whiteway, J., M. Daly, A. Carswell, C. Dickinson, T. Duck, L. Komguem, and C. Cook (2008), Lidar on the Phoenix mission to Mars, J. Geophys. Res., 113, E00A08, doi:10.1029/2007JE003002.

Yen, A. S., et al. (2005), An integrated view of the chemistry and mineralogy of Martian soils, Nature, 436, 49-54, doi:10.1038/nature03637.

Zent, A., M. Hecht, D. Cobos, G. Cardell, M. Foote, S. E. Wood, and M. Mehta (2008), The Thermal Electrical Conductivity Probe (TECP) for Phoenix, J. Geophys. Res., doi:10.1029/2007JE003052, in press.

R. E. Arvidson, Department of Earth and Planetary Sciences, Washington University, St. Louis, MO 63130, USA. 
D. Bass, D. Blaney, E. DeJong, M. Hecht, and L. Tamppari, Jet Propulsion Laboratory, California Institute of Technology, Pasadena, CA 91109, USA.

W. Boynton and P. H. Smith, Department of Planetary Sciences, University of Arizona, Tucson, AZ 85721, USA. (psmith@1pl.arizona.edu) A. Carswell, Optech Inc., Vaughan, ON L4K 5Z8, Canada.

D. Catling, Department of Earth Sciences, University of Bristol, Wills Memorial Building, Queen's Road, Bristol BS8 1RJ, UK.

B. Clark, Lockheed Martin, Littleton, CO 80125, USA.

T. Duck, Department of Physics and Atmospheric Science, Dalhousie University, Sir James Dunn Building, 6310 Coburg Road, Halifax, NS B3H 1Z9, Canada.

D. Fisher, Glaciology Section, Northern Division, Geological Survey of Canada, Natural Resources Canada, 562 Booth Street, Ottawa, ON K1A 0E8, Canada.

W. Goetz, S. Hviid, H. Keller, and W. Markiewicz, Max Planck Institute for Solar System Research, D-37191 Katlenburg-Lindau, Germany.

P. Gunnlaugsson, Department of Physics and Astronomy, University of Aarhus, Ny Munkegade, Aarhus C, DK-8000 Denmark.

V. Hipkin, Canadian Space Agency, Saint-Hubert, QC J3Y 8Y9, Canada. J. Hoffman, Physics Department, University of Texas, Dallas, TX 75080, USA.

S. Kounaves and S. Young, Department of Chemistry, Tufts University, Medford, MA 02155, USA.
C. F. Lange, Department of Mechanical Engineering, 4-9 Mechanical Engineering Building, University of Alberta, Edmonton, AB T6G 2G8, Canada.

M. Lemmon, Department of Atmospheric Sciences, Texas A\&M University, College Station, TX 77843, USA.

M. Madsen, Earth and Planetary Physics, Niels Bohr Institute, University of Copenhagen, Juliane Maries Vej 30, DK-2100 Copenhagen Oe, Denmark.

M. Malin, Malin Space Science Systems, P.O. Box 910148, San Diego, CA 92191-0148, USA.

J. Marshall, SETI Institute, Mountain View, CA 94043, USA

C. McKay, C. Stoker, and A. Zent, Space Science Division, NASA Ames Research Center, Moffett Field, CA 94035, USA.

M. Mellon, Laboratory for Atmospheric and Space Physics, University of Colorado, Boulder, CO 80309, USA.

D. Ming and R. Morris, Johnson Space Center, Houston, TX 77058, USA.

W. T. Pike, Department of Electrical and Electronic Engineering, Imperial College London, Exhibition Road, London SW7 2AZ, UK.

N. Renno, Department of Atmospheric, Oceanic and Space Sciences, University of Michigan, Ann Arbor, MI 48109, USA.

U. Staufer, Institute of Microtechnology, University of Neuchâtel, CH-2000 Neuchâtel, Switzerland.

P. Taylor and J. Whiteway, Department of Earth and Space Science and Engineering, York University, Toronto, ON M3J 1P3, Canada. 